\title{
Otoimmün Tiroid Bezi Hastalıklarında Tükürük Bezi Tutulumunun Tc-99m MIBI İle Değerlendirilmesi
}

\section{Detection of the involvement of salivary glands in autoimmune diseases of thyroid gland by using tc- $99 \mathrm{~m} \mathrm{MIBI}$}

\author{
Deniz Söylemez ', Gül Gümüşer ${ }^{2}$, Ebru Dursun Rükşen³ ${ }^{3}$ Elvan Sayıt Bilgin² \\ 1-Muğla Sıtkı Koçman Üniversitesi Eğitim Ve Araştırma Hastanesi Nükleer Tıp Kliniğ \\ 2-Celal Bayar Üniversitesi Nükleer Tıp AD \\ 3-Izmir Katip Çelebi Üniversitesi Eğitim Ve Araştırma Hastanesi Nükleer Tıp Kliniği
}

\section{öz}

Amaç: Bu çalışmanın amacı Graves hastalığı, Hashimoto tiroiditli ve kontrol grubundaki bireylerin, tükürük bezlerinde Tc99m Metoksiizobutrilizonitril (Tc-99m MIBI) tutulumunun değişimini araştırmaktır.

Gereç ve yöntem: Çalışma Ocak 2008 ve Aralık 2009 tarihleri arasında yürütüldü. 19 Graves hastası (6 erkek, 13 kadın), 28 Hashimoto tiroiditli hasta (5 erkek, 23 kadın) ve 11 kontrol olgusu (4 erkek,7 kadın) dosyaları retrospektif olarak değerlendirildi. Parotis ve submsndibular bezlerde Tc-99m MIBI tutulum değerleri, elips şeklinde ilgi alanları çizilerek ve formülüze edilerek hesaplandı.

Bulgular: Kontrol grubu, Graves hastalığı ve Hashimoto tiroiditi gruplarında, parotis bezlerinde Tc-99m MIBI tutulum değerleri arasında istatiksel açıdan anlamlı fark saptanmadı. Graves hastalığı ve Hashimoto tiroiditi gruplarında ve de kontrol grubunda submandibular bezlerde Tc-99m MIBI tutulum değerleri arasında istatiksel açıdan anlamlı fark saptandı $(\mathrm{p}<0.05)$.

Sonuç: Graves hastalığı ve Hashimato tiroiditi gruplarında submandibular bezlerde saptanan farklı Tc-99m MIBI tutulumunun kontrol grubuna göre değişiklik göstermesi otoimmünite, yüksek mitokondri sayısı ve inflamatuar reaksiyon gibi histopatolojik bulgularla ilgili olabileceğini düşündürmektedir.

Anahtar kelimeler: Otoimmün tiroid bezi hastalıkları, tükürük bezleri, Tc-99m MIBI

\section{ABSTRACT}

Aim: The aim of this study was to determine the involvement in the salivary glands of the patients with Graves' Disease, Hashimoto Thyroiditis and controls by detecting the changes of Tc-99m Methoxyisobutylisonitrile (Tc-99m MIBI) uptake.

Material and Methods: The study was conducted between January 2008 and December 2009. 19 patients with Graves' disease ( 6 men, 13 women), 28 Hashimoto Thyroiditis patients (5 men, 23 women) and 11 euthyroid controls ( 4 men, 7 women) were evaluated retrospectively. Uptake values of parotid and submandibular glands were calculated by drawing elliptical ROIs (region of interest) and using the formula for uptake calculation.

Result: In all three groups, in parotis glands, a statistical significant difference between Tc-99m MIBI uptake was not detected. The Tc-99m MIBI upateke values in submandibular glands were statistically different among patients with Graves'Disease, Hashimoto Thyroiditis, as well as in Control group $(\mathrm{p}<0.05)$.

Conclusion: We concluded that the different uptake values of Tc-99m-MIBI in submandibular glands in Graves disease and Hashimoto thyroiditis as compared to the control group patient would be results of the histopathological features, such as autoimmunity, high mitochondria number and inflammatory reaction.

Keywords: Autoimmune thyroid diseases, salivary glands, Tc99m MIBI 


\section{GíRiş}

Otoimmün tiroid hastalıkları dünyada sıkça rastlanan sağlık problemlerindendir. Graves hastalı̆̆ı ve Hashimoto tiroiditinden oluşan, en sık görülen otoimmün hastalıklardan olmakla birlikte, batılı toplumların \% 2-5'ini etkilemektedirler $(1,2)$. Tiroid otoimmünitesi çevresel, genetik ve endojen faktörlerin biraraya gelmesiyle tiroid bezinde $T$ ve $B$ lenfosit infiltrasyonu, tiroid otoantikorlarının üretimi ile ortaya çıkar. Bunların sonucunda farklı klinik belirtiler meydana gelir (3). Hashimoto tiroiditi en sık görülen otoimmün tiroid hastalığıdır. İyodun yeterli olduğu bölgelerde hipotiroidinin en sık nedenidir. Hastalı̆ın dönemlerine göre sintigrafik görünüm, radyoaktif maddenin değişken tutulumuna göre farklılık gösterebilir $(4,5)$. Graves hastalığı; tirotoksikoz, diffüz guatr, infiltratif oftalmopati ve nadiren infiltratif dermopati ile karakterizedir (6). Graves hastalığı, hipertiroidizm olgularının \% 60-80'ini oluşturur. Hastalarda genellikle diffüz büyük tiroid bezi ve tiroid bezinde radyoaktivite tutulumunda artış gözlenir (7).

Tiroid sintigrafisinde günümüzde en sık kullanılanı Teknesyum-99m (Tc-99m) perteknetattır. Diğerleri ise; lyot-131 (I-131), Iyot-123 (I-123), Talyum-201 (TI-201), Tc-99m Metoksi-izobütil-izonitril (Tc-99m MIBI), Flor18 Florodeoksiglikoz (F-18 FDG), lyot-131 Metaiyodobenzilguanidin (I-131 MIBG), İndium -111 (I-111)'dir (4). TC-99m Metoksiizobutrilizonitril (Tc-99m MIBI) miyokard iskemisinin, paratiroid patolojilerinin belirlenmesi ve tümör tarama ajanı olarak kullanılmaktadır (5). Katyonik lipofilik Tc-99m MIBI'nin fizyolojik tutulum alanları arasında tiroid bezide vardır. Sağlam hücre membranı varlığında Tc-99m MIBI uptake ve retansiyona uğrayabilir, hücre membranından pasif difüzyonla geçer, elektrostatik çekim nedeniyle \%90'ı mitokondride birikir. Birçok bilim adamı Tc-99m MIBI'nin tiroid bezindeki tutulumunun
TSH düzeyinden bağımsız olduğunu, baskılanmış tiroid dokusunda da tutulum olabileceğini göstermiştir. Böylece Tc-99m MIBI hasta hazırlığı gerekmeden tiroid sintigrafisi yapabilmeyi mümkün kıldığını bildirmişlerdir $(3,6,7)$.

Otoimmün tiroiditli hastalarda tükürük bezlerinde Tc-99m MIBI tutulumunu araştıran az sayıda çalışma bulunmaktadır. Bu nedenle çalışmamız 2008 yılında Celal Bayar Üniversitesi Nükleer Tıp Anabilim Dalında Graves hastalığı ve Hashimoto tiroiditli bireylerin tiroid bezinde Tc-99m MIBI tutulumu araştıran çalışmanın devamı niteliğindedir (8). Çalışmamızda otoimmün tiroiditli hastalarda tükürük bezlerinde Tc-99m MIBI tutulumunun otoimmüniteden etkilenip normal bireylerle farklılık gösterip göstermediğini saptamayı amaçladık.

\section{GEREÇ ve YÖNTEM:}

\section{Hasta seçimi:}

Çalışma Ocak 2008 - Aralık 2009 yılları arasında Celal Bayar Üniversitesi Nükleer Tıp Anabilim Dalı'nda Tc-99m MIBI tiroid sintigrafisi tetkiki yapılmış; endokrinoloji kliniği tarafından tanı konulmuş 19 Graves hastası, 28 Hashimoto tiroiditi ve 11 kontrol olgusunu içermektedir. Hastalara ait dosyalar retrospektif olarak incelendi. 11 kontrol olgusu ise kliniğimize miyokard perfüzyon sintigrafisi için gelen bilinen tiroid ve tükürük bezi hastalığı olmayan, ötiroid hastalardan oluşturuldu. TC-99m MIBI tiroid sintigrafisi görüntülerinde tükürük bezlerinde Tc-99m MIBI tutulumları değerlendirildi.

\section{Deneysel model:}

Olgulara $370 \mathrm{MBq}(10 \mathrm{mCi})$ Tc-99m MIBI intravenöz yoldan verildi (9). Görüntüleme için çift başlı gama kamera (Infinia, GE Medical 
Systems, Tirat Hacermel, Israel) ve paralel delikli, düşük enerjili, yüksek rezolüsyonlu (LEHR) kolimatörler (Infinia, GE Medical Systems, Tirat Hacermel, Israel) kullanılmış, enjeksiyon öncesinde ve sonrasında dolu ve boş şırıngalar 2 saniyelik süreyle 2 zoomda görüntülenmiştir. Tüm hastalarda 20. ve 120.
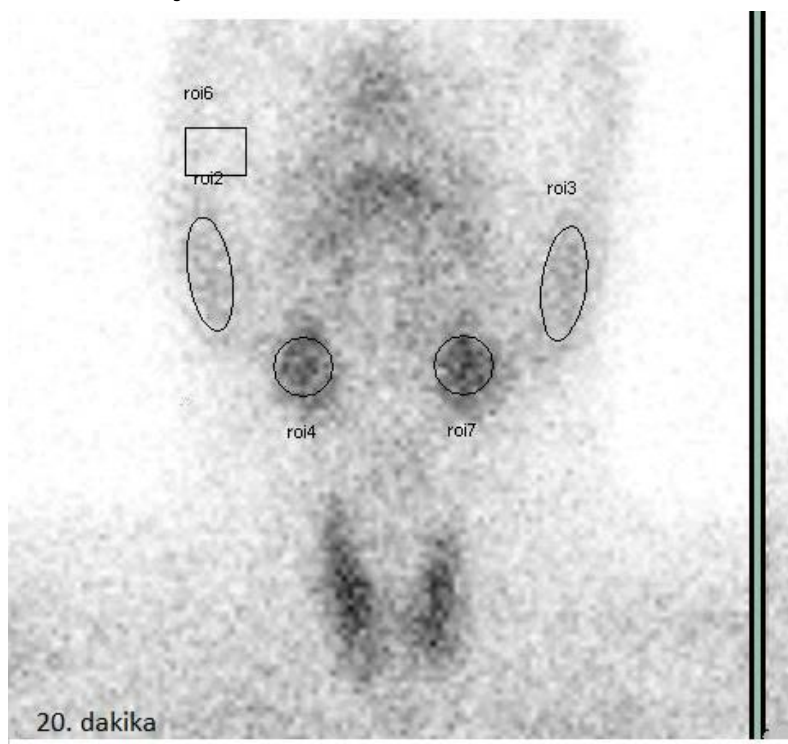

dakikalarda statik görüntüler alınmıştır. Üç gruba ait görüntüler kullanılarak 20. ve 120 . dakikalarda parotis ve submandibular bezlere elips şeklinde irregüler tarzda zemin aktivite içinde suborbital alana eşit büyüklükte ilgi alanları çizildi (Şekil-1-2-3).

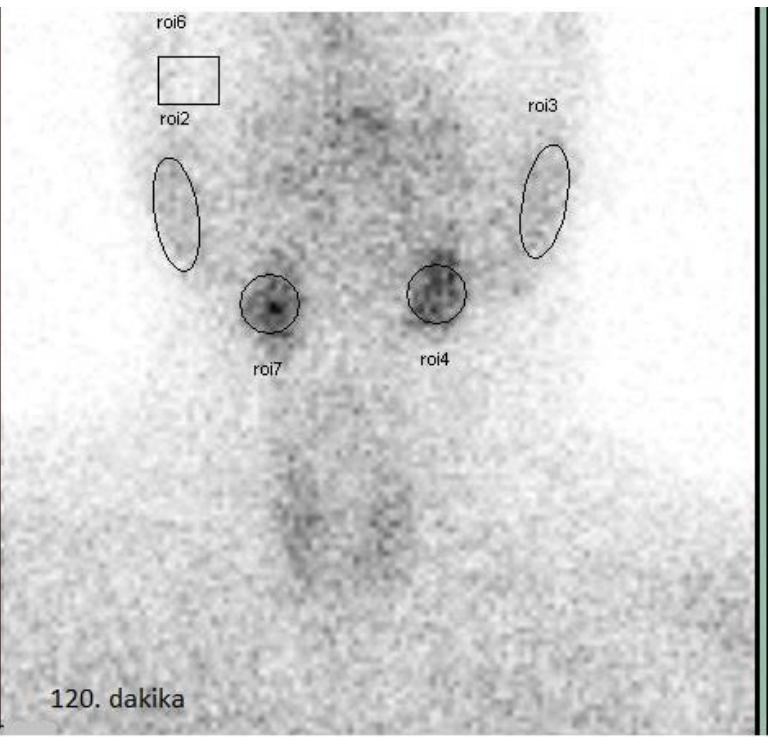

Şekil-1 Hashimoto hastalarında 20. ve 120. dakikalarda tükürük bezleri ve arka plana ROİ çizimi

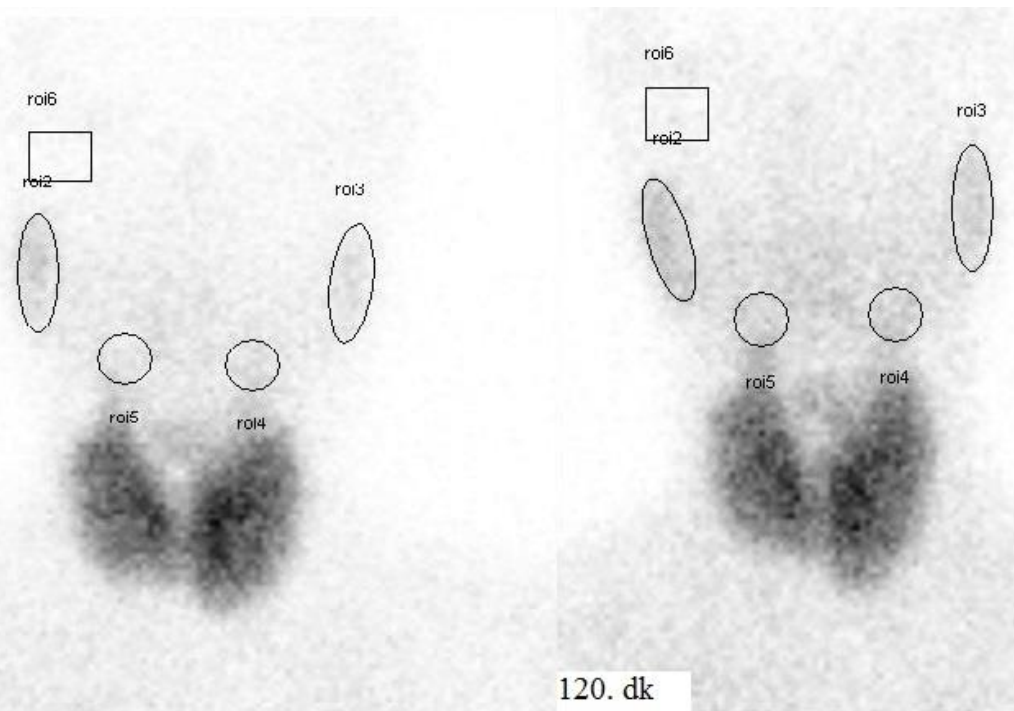

ŞEKIL-2 Graves hastalarında 20. ve 120 . dakikalarda tükürük bezleri ve arka plana ROİ çizimi 


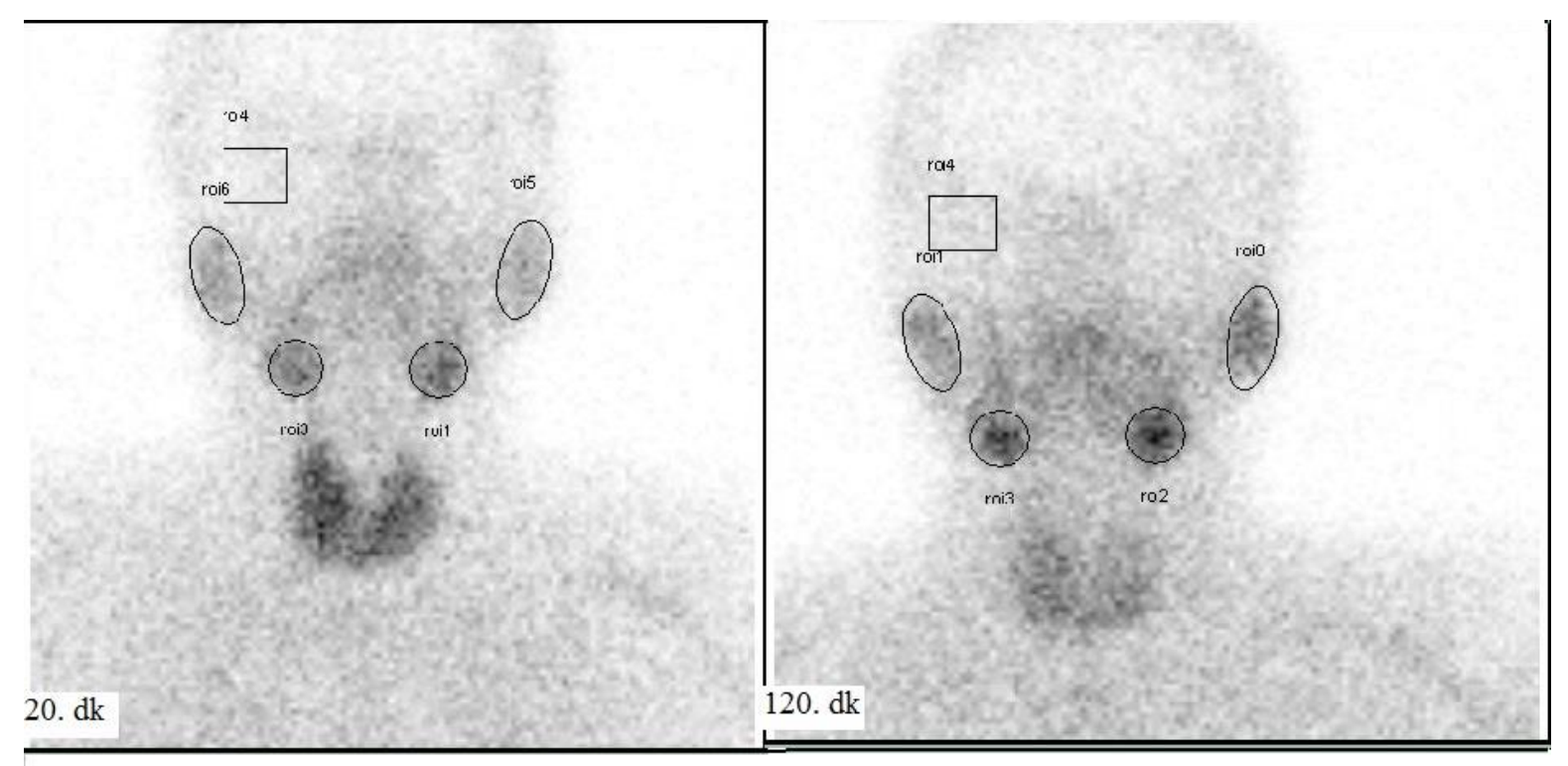

ŞEKIL-3 Kontrol gurubunda 20. ve 120. dakikalarda tükürük bezleri ve arka planda ROİ çizimi

Tükürük bezlerinde Tc-99m MIBI tutulum değerleri aşağıdaki formülle hesaplandı (9).

\section{T - Z.A}

$\mathrm{TT}(\%)=----\times 100$

B - A

TT : Tükürük bezinde MIBI Upatake (\%)

$T$ : Tükürük bezi sayımı

\section{Z.A : Zemin Aktivite}

B : Dolu şırınga sayımı,

A : Boş şırınga sayımı.

İstatistiksel analiz:

İstatistiksel analizde SPSS 15 istatistik paket programında ki kare testi, Kruskal Wallis varyans analizi ve Spearman korelasyon analizi kullanıldı. Mann-Whitney $U$ testi kullanılarak farkı yaratan grup belirlendi. $p<0.05$ istatiksel açıdan anlamlı düzey olarak kabul edildi.
2011 yılında Celal Bayar Üniversitesi Tıp Fakültesinden yerel etik kurul onayı alındı.

\section{BULGULAR}

Çalışmamızda Tc-99m MIBı tiroid sintigrafisi tetkiki yapılan toplam 58 hastanın; 19'u Graves hastası (6 erkek,13 kadın; yaş ortalaması: $34.5 \pm 11.8 \mathrm{yıl}$ ), 28'i Hashimoto tiroiditi (5 erkek, 23 kadın; yaş ortalaması: 44,5 \pm 10.9 yıl) ve 11 'i kontrol olgusu (4 erkek, 7 kadın; yaş

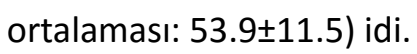

Graves hastalığı, Hashimoto tiroiditi ve kontrol grubu hastalarının tükürük bezlerinde 20. ve 120. dakikalarda Tc-99m MIBI tutulumları hesaplandı. Tüm gruplardaki submandibular ve parotis bezlerindeki Tc-99m MIBI uptake yüzdelerinin ortalama değerleri Tablo 1 de gösterilmiştir. 
Tablo 1: Hashimato Tiroiditi, Graves Hastalığı ve kontrol grubunda submandibular ve parotis bezlerinde Tc-99m MIBI uptake \% oranları

\begin{tabular}{llll} 
Tablo 1: Hashimato Tiroiditi, Graves Hastalığı ve kontrol grubunda submandibular ve parotis bezlerinde Tc-99m MIBI uptake oranları \\
\hline
\end{tabular}

Graves hastalığı, Hashimoto tiroiditi ve kontrol gruplarında submandibular bezlerde 20. dakikada $(p=0.004), 120$. dakikada $(p=0.002)$ Tc-99m MIBI tutulum değerleri arasındaki fark istatiksel açıdan anlamlı fark tespitedildi. 20. ve 120 dakikalarda submandibular bezlerde kontrol grubu, Graves hastalığı grubu ve Hashimoto tiroiditi grupları arasında en yüksek Tc-99m MIBI tutulumu Hashimoto tiroiditi grubundayken kontrol grubunda ise en düşük tutulum değerleri saptandı.

Hashimoto grubunda, kontrol grubuna göre submandibular bezlerde 20 . dakikada $(p=0.009)$ ve 120. dakikada ( $p=0.011)$ Tc-99m $\mathrm{MIBI}$ tutulum değerleri arasında istatiksel olarak anlamlı fark tesbit edildi. Tc-99m MIBI tutulumu Hashimoto tiroiditi grubunda kontrol grubuna göre fazla olarak bulundu. Graves hastalarında, kontrol grubuna göre submandibular bezlerde 20.dakikada Tc-99m MIBI tutulumunda istatiksel olarak anlamlı fark saptandı $(p=0.004)$. Ancak Graves hastalarında 120. dakikalarda submandibular bezlerde MIBI tutulumunda istatiksel açıdan anlamlı fark saptanmamasına rağmen ortalama değerlerin kontrol grubuna göre belirgin yüksek olduğu gözlendi ( $p=0.068$ ).

Graves hastalığı, Hashimoto tiroiditi ve kontrol gruplarında parotis bezlerinde 20 . dakikada $(p=0.164), 120$. dakikada $(p=0.236)$ Tc-99m MIBI tutulum değerleri arasında istatiksel açıdan anlamlı fark saptanmadı. Ancak 20. dakikada parotis bezlerinde kontrol grubu, Graves hastalığı grubu ve Hashimoto tiroiditi grupları arasında en yüksek Tc-99m MIBI tutulumu Hashimoto tiroiditi grubundaydı. Kontrol grubunda ise en düşük tutulum değerleri saptandı. 120. dakikada parotis bezlerinde Graves hastalığı grubu ve Hashimoto tiroiditi grupları arasındaki Tc-99m MIBI tutulumu eşitken; kontrol grubunda ise en düşük tutulum değerleri saptandı.

Kontrol, Graves hastalığı ve Hashimoto tiroiditi gruplarının 20. ve 120. dakika tutulum değerleri ile otoantikor değerleri arasında korelasyon analizi yapıldığında anlamlı bir ilişki belirlenememiştir $(p=0,06)$.

\section{TARTIŞMA:}

Otoimmün tiroiditli hastalarda tükrük bezlerinde Tc-99m MIBI tutulumunu araştıran az sayıda litaratür bulunmaktadır. Daha çok otoimmün hastalıklarda (sjögren sendromu, romatoid artirit, otoimmün tiroiditler v.b.) tükürük bezlerinin Tc-99m perteknetat tükrük bezi sintigrafisi ile fonksiyonel durumunu araştıran çalışmalar mevcuttur.

Otoimmun hastalıklarda tükrük bezi fonksiyonlarının sintigrafik olarak değerlendirilmesi amacıyla Süslü ve arkadaşları tarafından yapılan çalışmada romatoid artirit, sjögren sendromu, hashimato tiroiditi tanısı olan hastalar araştırmaya dahil edilmiştir. $\quad 370 \mathrm{MBq} \quad(10 \mathrm{mCi}) \quad$ Tc-99m perteknetat intravenöz olarak enjekte edildikten sonra çalışmanın 30 . dakikasında 3 $\mathrm{ml}$ limon suyu hastaya verilmiş; her iki parotis ve submandibular tükrük bezleri 
değerlendirmeye alınmıştır. Tükrük bezlerine ve sağ orbita üzerine arka plan için Rol'ler çizilip semikantitatif olarak tükrük bezi fonksiyonları hesaplanmıştır. Sintigrafik olarak parotis bezi fonksiyonu, romatoid artiritli grup ve sjögrenli hastalarda parotis bezi üzerine çizilen ilgi alanlarından elde edilen verilere göre hashimoto tiroiditine göre daha düşük bulunmuştur $\quad(p=0.001)$ Submandibular bezlerde ise Hashimoto grubunda tükrük bezi fonksiyonları bozulmuş olarak tespit edilmiştir $(p=0.018) \quad$ (10). Bizim çalışmamızda da Hashimoto grubunda submandibular bezlerde Tc-99m MIBI tutulumu kontrol grubuna ve Graves grubuna göre anlamlı derecede yüksek tespit edildi.

Santos ve arkadaşlarının yaptığı çalışmada Graves hastalıklı, Hashimoto tiroiditli bireylerde ve kontrol olgularında tiroid bezinde Tc-99m MIBI tutulumu araştırılmıştır. Tüm gruplarda Tc-99m MIBI görüntülerinden aktivitenin yarılanma zamanı $\left(T \frac{1}{2}\right)$, maksimum aktiviteye ulaşma zamanı (Tmax) değerleri hesaplanarak Tc-99m MIBI tutulumlarının tedaviden, TSH değerlerinden etkilenip etkilenmediği araştırılmıştır. Graves hastalığı, Hashimoto tiroiditi ve kontrol grubu hastalarının kan otoantikor düzeyleri ile Tc99m MIBI tutulumları arasındaki ilişki saptanmaya çalışılan bu çalışmaya 30 Graves hastalıklı, 30 Hashimoto tiroiditli (15 atrofik,15 hipertrofik formda), 40 kontrol grubu dahil edilmiştir. Tüm gruplara Tc-99m MIBI tiroid sintigrafisi uygulanmıştır. Hastalara LEHR kolimatör altında $370 \mathrm{MBq}(10 \mathrm{mCi}) \mathrm{Tc}-99 \mathrm{~m}$ MIBI intravenöz yoldan verilerek dinamik çekim yapılmıştır. Tüm hastalara 20. dakika, 1. ve 2 . saatlerde tiroid bezi statik görüntüleri alınmış. Dinamik görüntülerde tiroid ve altındaki bölgeden zemin ilgi alanı alınarak yapılan çizimlerden elde edilen zaman-aktivite eğrilerinden $T^{1} / 2$ ve Tmax, tiroid bezindeki Tc99m MIBI tutulumu hesaplanmıştır. Sonuç olarak Gravesli hastalarda tiroid bezinde Tc- 99m MIBI tutulumunun yüksek olduğu belirlenmiştir (9). Benzer şekilde bizim çalışmamızda da hastalara Tc-99m MIBI intravenöz yoldan verilerek 20. ve 120 . dakikalarda tükrük bezlerine statik görüntüler alınmıştır. Gravesli hastalarda submandibular bezlerde Tc-99m MIBI tutulum değerlerinin kontrol grubuna göre yüksek olduğunu saptanmıştır. Santos ve arkadaşlarının ve de bizim çalışmamızda da bu durumun tiroid bezindeki inflamasyona bağlı olarak kan akımında, membran geçirgenliğinde, mitokondri sayısında artışa bağlı olabileceği düşünülmüştür.

Changlai ve arkadaşlarının yapmış olduğu çalışmada özellikle ekzokrin bezleri etkileyen, kronik, otoimmün, inflamatuar bağ dokusu hastalığı olan Sjögren sendromlu hastalarla histopatolojik olarak, tükürük bezlerinde lenfositik infiltrasyonun otoimmun tiroiditli hastalarla benzer özellik gösterdiği belirtilmiştir. Çalışmaya 10 yılı aşkın otoimmun tiroidit öyküsü bilinen 40 hasta ve 61 sağlıklı kontrol olgusu alınarak $5 \mathrm{mCi}$ Tc-99m perteknetatın intravenöz enjeksiyondan sonra 30 dakika süreyle ardışık görüntüler elde edilerek, tükürük atılımı 200 mg askorbik asit ile 15. dakikada sitimüle edilmiştir. Tükürük bezlerine ve arka plana ROI çizilerek maksimum atılım oranı hesaplanmıştır. İstatiksel olarak anlamlı fark bulunarak, kontrol grubuna göre otoimmun tiroiditli bireylerde tükrük bezi fonksiyonlarının anlamlı derecede bozulduğu bildirilmiştir (11). Biz bu çalışmadan farklı olarak Tc-99m perteknetat yerine Tc-99m MIBI'yi kullanarak tükrük bezlerini değerlendirdik. Biz de çalışmamızda otoimmun tiroiditli bireylerde submandibular bezlerde Tc99m MIBI tutulumunun kontrol gurubuna göre yüksek olduğunu saptadık.

Kao ve arkadaşları yaptıkları bir çalışmada 14 hipertiroidili ve 10 normal bireyde $370 \mathrm{MBq}$ (10 mCi) Tc-99m MIBI enjeksiyonu sonrası pinhole kolimatör ile görüntüleme yaparak 
tiroid bezinde Tc-99m MIBI tutulumu araştırmışlardır. Bu çalışmada hipertiroidili bireylerde tiroid bezinde Tc-99m MIBI tutulumun sağlıklı bireylere göre yüksek olduğu ve hipertiroidi tanısında Tc-99m MIBI tutulumunun kullanılabileceği bildirilmişlerdir (p <0.005) (12). Bizim çalışmamızda da hipertiroidi tablosunda bulunan Graves hastalıklı grupta submandibular bezlerdeki Tc$99 \mathrm{~m} \mathrm{MIBI}$ tutulumu kontrol grubuna göre yüksek bulundu. Graves hastalığı grubunda submandibular bezlerde MIBI tutulumunun yüksek olarak saptanmasının kan akımı artışına ve mitokondri sayısının artışına bağlı olduğu düşünülmüştür. Ayrıca Hashimoto tiroiditi ile kontrol grubunda da Tc-99m MIBI tutulum değerleri arasında Hashimoto tiroiditli olgular lehine anlamlı farklılık saptanmıştır.

Koczor Rozmusa ve arkadaşlarının yapmış olduğu çalışmada otoimmun tiroid bezi hastalıklı ve sağlıklı gönüllülerde tükrük bezi salgısının tiroid hormonlarından etkilenip etkilenmediği araştırılmış ve bu amaçla çalışmaya 106 otoimmun tiroiditli kadın hasta ve 15 sağlıklı gönüllü alınarak tükrük bezi fonksiyonları incelenmiştir. Olguların hipotiroidi, hipertiroidi durumu, tiroid otoantikorlarının (TPO-Ab, Tg-Ab, TR-Ab) kandaki konsantrasyonu belirlenmiştir. Olgulara Tc-99m tükrük bezi sintigrafisi uygulanmıştır. Bazal ve uyarılmış tükrük bezi salgı hacmi hesaplanmıştır. Hipotiroidi tablosundaki otoimmun tiroiditli bireylerde tükrük bezi salgı miktarı düşük (\%57) saptanırken, hipertiroidili hastalarda tükrük bezi salgı miktarının daha fazla olduğu (\%75) belirlenmiştir. Sonuç olarak tükrük bezi salgısının tiroid hormon üretiminden, kandaki tiroid otoantikor konsantrasyonundan etkilendiği ve bu olayın tükrük bezindeki otoimmun süreçlerle ilgili olduğu ileri sürülmüştür (13). Bizim çalışmamızda da otoimmun tiroiditli hastalarda tükrük bezlerinde Tc-99m MIBI tutulumu yüksek saptanmıştır. Bu durumun otoimmuniteye sekonder kan akımı ve mitokondri sayısındaki artış ile ilişkili olduğu düşünülmüştür.
SONUÇ:

Graves hastalığı ve Hashimato tiroiditi gruplarında submandibular bezlerde saptanan farklı Tc-99m MIBI tutulumunun kontrol grubuna göre değişiklik göstermesi otoimmünite, yüksek mitokondri sayısı ve inflamatuar reaksiyon gibi histopatolojik bulgularla ilgili olabileceğini düşündürmektedir. Bu bulgular ışığında, Tc-99m MIBI tiroid sintigrafisinin otoimmun tiroiditli hastalarda tükrük bezlerinin etkilenip etkilenmediğini gösterebileceğini düşünüyoruz. Bu durumun, her iki hastalığın değişik safhalarında daha geniş sayıda hasta içeren araştırmalar ile teyidine gereksinim vardır.

\section{KAYNAKLAR:}

1. Collins J, Gough S. Autoimmunity in thyroid disease. Eur J Nucl Mol Imaging 2002;29(2):s417-24.

2. Weetman AP. Autoimmune thyroid disease: propagation and progression. Eur. J. Endocrinol. 2003;148(1):1- 9.

3. Vattimo A, Berteli $P$, Burroni L. Effective vizualization of supressed thyroid tissue by means of baseline Tc- $99 \mathrm{~m}$ methoxy isobutyl isonitrile Comprasion with Tc-99m pertechnetate scintigraphy after TSH stimulation. J. Nucl. Biology and Med. 1992; 36: $315-8$.

4. Harvey A.Ziessman, Janis P.O'Malley, James H. Thrall. The Requisıtes Nuclear Medicine Missouri A Harcourt Health Sciences Company, 2006: 71 -112

5. Abdelhamid H. Elgazzar. The Pathophysıologıc Basıs of Nuclear Medicine Berlin: Springer 2001: 127 -140.

6. Michael A.Wilson. Texbook of Nuclear Medicine. Jesus A.Bianco and Michael A. Wilson. Philadelphia, Lippincott.1998: 34.

7. Erdil TY, Öncel Ç, Kanmaz B et al. Comprasion of $99 \mathrm{~m}$ Tc MIBI and TI -201 scintigraphy in vizulation of supressed thyroid tissue. Eur J Nucl Med 2000; 41(7): 1163-67.

8. Rükşen E., Sayıt E. Otoimmun tiroiditli bireylerde (hashimoto tiroiditi ve Graves hastalıklı) Tc-99m MIBI tutulumunun ötiroid bireylerle karşılaştırılması Uzmanlık tezi Celal Bayar Üniversitesi, 2009

9. Santos A O, Zantut -Wittmann D E, Nogueira R O et al. Tc-99m sestamibi thyroid uptake in Euthyroid individuals and in patients with autoimmune thyroid disease. Eur J Nucl Med. 2005; 32(6):702-

10. Süslü H., Yıldız M. Otoimmun hastalıklarda tükürük bezi fonksiyonlarının sintigrafik olarak değerlendirilmesi. Uzmanlık tezi Süleymen Demirel Üniversitesi, 2007

11. Changlai SP, Chen WK, Chung $C$ et al. Objective evidence of decreased salivary function in patients with autoimmune thyroiditis (chronic thyroiditis, Hashimoto's thyroiditis) Nucl Med Commun $2002 ; 23(10): 1029-33$

12. Kao $\mathrm{CH}$, Wang SJ, Liao SQ et al. Quick diagnosis of hyperthyroidism with semiquantative 30 -minute technetium-99m methoxy-isobutyl-isonitrile thyroid uptake. Eur J Nucl Med1993;34(1):71-4.

13. Koczor RA, Zwirska KK, Sadlak NJ et al. Evaluation of salivary gland function in women with autoimmune thyroid diasesed Eur J Nucl Med. 2003;56(9-10):412-8.

Bu çalışma "24. Annual Congress of the Europen Association of Nukleer Medicine EANM October 2011 Birmingham" kongresinde poster olarak sunulmuştur. 